Proceeding Paper

\title{
Influence of Selected Material and Process Parameters on the Durability of Briquettes Made of Shredded Logging Residues ${ }^{\dagger}$
}

\author{
Tomasz Nurek*, Arkadiusz Gendek and Magdalena Dąbrowska
}

Citation: Nurek, T.; Gendek, A.;

Dąbrowska, M. Influence of Selected Material and Process Parameters on the Durability of Briquettes Made of Shredded Logging Residues. 2021, 3, 6. https://doi.org/10.3390/ IECF2020-07777

Academic Editors: Angela Lo Monaco; Cate Macinnis-Ng and Om P. Rajora

Published: 10 November 2020

Publisher's Note: MDPI stays neutral with regard to jurisdictional claims in published maps and institutional affiliations.

Copyright: (C) 2020 by the authors. Licensee MDPI, Basel, Switzerland. This article is an open access article distributed under the terms and conditions of the Creative Commons Attribution (CC BY) license (http://creativecommons.org/licenses/by/4.0/).

\author{
Department of Biosystems Engineering, Institute of Mechanical Engineering, Warsaw University of Life \\ Sciences-SGGW, Nowoursynowska 164, 02-787 Warsaw, Poland; arkadiusz_gendek@sggw.edu.pl (A.G.); \\ magdalena_dabrowska@sggw.edu.pl (M.D.) \\ * Correspondence: tomasz_nurek@sggw.edu.pl \\ † Presented at the 1st International Electronic Conference on Forests - Forests for a Better Future: Sustainability \\ Innovation, Interdisciplinarity, 15-30 November 2020; Available online: https://iecf2020.sciforum.net.
}

\begin{abstract}
The nonhomogeneous physical properties of the raw material in the form of shredded logging residues, and its composition may cause a serious problem in its further use. As a result of conducted research, it was found that the elemental composition of logging residues (low nitrogen and ash contents) is suitable for raw materials dedicated to energy use. The possibility of using this raw material for the production of briquettes and the correlation between the physical properties of the final product and the parameters of the raw material and the briquetting process were also determined. The material used for tests was wood chips with moisture contents of $10 \%, 15 \%, 20 \%$, compacted in a closed chamber at the temperatures of 22,73 and $103{ }^{\circ} \mathrm{C}$ at unit pressures of approx. $65 \mathrm{MPa}$. The best results were obtained for the material moisture content of $10 \%$. It was found that the temperature of the wood chips during agglomeration influences the degree of compaction and durability of the obtained briquettes. It is more advantageous to conduct compaction at a higher temperature. The research also determined the effect of the fractional composition of the briquetted mixture divided into size groups $0-1,1-4,4-8$, and $8-16 \mathrm{~mm}$, its moisture and temperature of the process on the durability of the product. On the basis of the obtained results, the most favorable fractional composition of the briquetted mixture, its moisture and temperature of the compaction process were determined.
\end{abstract}

Keywords: forest; biomass; pressure; agglomeration; briquette; durability; logging residues

\section{Introduction}

Recent years have been a time of increasing demand for biomass used as a raw material for the production of liquid and gaseous fuels, intended for direct combustion or for the production of refined fuels in the form of briquettes or pellets. It is directly related to the prevention of climate change, which for many years has been the subject of research and development of new methods of heat and electricity production. One type of biomass that has not been fully used so far are logging residues and by-products of the forestry production processes. The logging residues are the material that is created during the harvesting of thick wood, as well as during the maintenance and cleaning of forest stands. For sanitary and fire protection reasons, this raw material should not remain in its natural form on forest surfaces. It must be cleaned up prior to the commencement of works related to the restoration of the stand. Some researchers also highlight the importance of forestry residues for the quality of forest soils. However, attention should be paid to the fact that during the several decades of stand development, a significant amount of substances enriching the habitat accumulated in the soil (drooping needles, drooping leaves, dying plants of the 1st floor undergrowth). A solution that also reduces the risk of fire, cleans the surface, preparing it for afforestation and at the same time does not impoverish the 
soil, is to crush the residues and mix them with the top layer of soil. This solution, however, entails considerable costs. The literature defines this material as logging residues. A characteristic feature of this type of biomass is its heterogeneity. Apart from pure, white wood, it contains a large amount of bark, pine needles and unlignified young shoots.

The usefulness of biomass as an energy raw material is proved, inter alia, by its elemental composition. The contents of CHNS, oxygen and ash is relatively well known for wood of various species and wood waste [1], individual parts of trees [2] that may be found in forest chips [3], such as: wood, stumps, roots, bark, needles, cones, seeds [4].

The aims of the research were (1) to determine the elemental composition and energy properties of the tested raw material; (2) to determine the possibility of using shredded material for briquette production, as well as (3) to determine the most favorable, from the point of view of briquette durability [5], the fractional composition of the compacted biomass and process parameters.

\section{Materials and Methods}

The research material consisted of logging residues obtained in the process of harvesting wood in an 80-year-old pine stand (Pinus silvestris L.), crushed with a hammer shredder (BT 13HP-90 mm (REDMET, Dębica, Poland) into chips with dimensions not exceeding $16 \mathrm{~mm}$. The wood chips, apart from the elements of white wood, contained a considerable amount of needles and small diameter nonwoody shoots. Due to the nature of the obtained material, the examined biomass did not contain the bark of the main tree part, but only the outer, poorly developed parts of the shoots, which were not white wood.

Samples of $50 \pm 0.5 \mathrm{~g}$ were weighed on the electronic scales RADWAG WTC 600 (RADWAG, Radom, Poland) with an accuracy of $\pm 0.01 \mathrm{~g}$ and then were placed in the laboratory drier UF55 plus (Memmert, Schwabach, Germany) at $105^{\circ} \mathrm{C}$ for $24 \mathrm{~h}$. Moisture content (MC, $\%$ ) was determined using a formula:

$$
M C=\frac{m_{b w}-m_{b d}}{m_{b w}} \cdot 100 \%
$$

where $m_{b w}$ is a mass of wet sample (g), $m_{b d}$ is a mass of dry sample (g).

The chips with moisture contents of $10 \%, 15 \%, 20 \%$ were compacted in a closed chamber at unit pressures of about $65 \mathrm{MPa}$ at temperatures of 22 and $73^{\circ} \mathrm{C}$ [6-8]. Each test was done in triplicate.

The influence of the fractional composition of the briquetted mixture, its moisture content, and the temperature of the compaction process on the durability of the product was made for the wood chips prepared by mixing the separated size fractions in various proportions. The analysis of the carbon, hydrogen, nitrogen, and sulfur contents (CHNS) was performed using the Elementar Vario Macro apparatus according to the procedure described by Sadhukhan et al. [9]. Elementar Vario Macro apparatus (Elementar Americas Inc., Ronkonkoma, USA) pursuant to the protocol given by Sadhukhan et al. (2009). Then the sample of raw material was incinerated, determining the ash and oxygen contents. The share of oxygen was determined on the basis of the content of other elements and ash in the analyzed material. The mechanical durability of briquettes was determined according to the EN-ISO 17831-2:2015 standard using the durability test stand. The durability of briquettes was determined by dimensionless durability coefficient $(\Psi)$ as a ratio of mass that remained after the analysis on the screen to the total mass of analyzed briquettes:

$$
\Psi=\frac{m_{p t}}{m_{p}} \cdot 100
$$

where $m_{p t}$ is a mass of briquettes after the durability test $(\mathrm{g}), m_{p}$ is a mass of briquettes before the durability test $(\mathrm{g})$. 


\section{Results}

Detailed results of the research on the elemental composition of the analyzed biomass are presented in Table 1. The percentage of elements and mineral compounds refers to the mean value obtained from the measurements.

Low content of nitrogen and sulfur $(0.66 \%$ and $0.25 \%)$ and a significant share of carbon (over 50\%) prove the possibilities of using pine logging residues as an energy raw material. Taking into account the low content of nitrogen and sulfur, low emission of harmful substances such as nitrogen oxides, benzene, and formaldehyde in the combustion process can be expected. The carbon content results in the calorific value of this biomass, encouraging further research.

Table 1. The share of elements and mineral compounds in the tested raw material and comparative materials (SD-standard deviation; for $C F_{(2,11)}=1127.9, p=1 \times 10^{-5}$; for $\mathrm{H} F(2,11)=0.02, p=1 \times 10^{-3}$, for $\mathrm{N} F(2,11)=155.15, p=8 \times 10^{-6}$, for $S F_{(2,11)}=6.69, p=0.01$, for $\mathrm{O} F(2,11)=0.02, p=0.17$, for Ash $F_{(2,11)}=$ $\left.178.56, p=4 \times 10^{-10}\right)$.

\begin{tabular}{ccccccc}
\hline \multirow{2}{*}{ Raw Material } & $\mathbf{C}$ & $\mathbf{H}$ & $\mathbf{N}$ & $\mathbf{S}$ & $\mathbf{O}$ & Ash \\
\cline { 2 - 7 } & \multicolumn{7}{c}{ Mean $( \pm$ SD), \% } \\
\hline \multirow{2}{*}{ Logging residues } & 50.84 & 5.72 & 0.66 & 0.25 & 41.46 & 1.07 \\
& $( \pm 0.07)$ & $( \pm 0.16)$ & $( \pm 0.06)$ & $( \pm 0.13)$ & $( \pm 0.07)$ & $( \pm 0.09)$ \\
Energy chips & 49.95 & 5.76 & 0.27 & 0.12 & 41.99 & 1.91 \\
& $( \pm 0.08)$ & $( \pm 0.05)$ & $( \pm 0.02)$ & $( \pm 0.01)$ & $( \pm 0.05)$ & $( \pm 0.11)$ \\
Wood saw chips & 48.42 & 5.64 & 0.41 & 0.10 & 43.01 & 2.42 \\
& $( \pm 0.08)$ & $( \pm 0.06)$ & $( \pm 0.02)$ & $( \pm 0.01)$ & $( \pm 0.03)$ & $( \pm 0.11)$ \\
\hline
\end{tabular}

The preliminary studies on compaction were performed for the unmodified fractional composition of the compacted biomass. Four fractions of compacted particles were distinguished (0-1 mm), (1-4) $\mathrm{mm},(4-8 \mathrm{~mm})$, and $(8-16 \mathrm{~mm})$. Their 'natural' shares in the wood chips were $6.32 \%, 32.52 \%, 36.14 \%$, and $25.02 \%$, respectively. The research allowed to find that the highest, although unsatisfactory, values of the durability coefficient were obtained in the case of compaction of biomass with a moisture of $10 \%$ (Table 2). These studies also allowed to reject the temperature of $22^{\circ} \mathrm{C}$ as too low to ensure the correct course of the process and the occurrence of the phenomena desired in the agglomeration process.

Table 2. Mean values of durability coefficient for briquettes made of material with 'natural-unmodified fractional composition' $\left(F_{(2,6)}=17.132 ; p=0.003\right)$.

\begin{tabular}{ccc}
\hline Moisture Content, $\%$ & Temp. $^{\circ} \mathbf{C}$ & Durability Coefficient ( \pm SD) \\
\hline \multirow{2}{*}{10} & 22 & $16.5( \pm 3.2)$ \\
& 73 & $22.4( \pm 2.6)$ \\
\multirow{2}{*}{15} & 22 & $16.7( \pm 1.8)$ \\
& 73 & $17.3( \pm 1.9)$ \\
\multirow{2}{*}{20} & 22 & $8.4( \pm 2.7)$ \\
& 73 & $12.3( \pm 1.1)$ \\
\hline
\end{tabular}

The results of the main series of tests (for the material with modified fractional composition) are presented in Table 3. Briquetting was carried out for two temperatures (73 and $103{ }^{\circ} \mathrm{C}$ ) and moisture equal to $10 \%$. In all cases, the briquette's mechanical durability coefficient ranging from $42 \%$ to $72.5 \%$ was unsatisfactory and lower than $80-98 \%$ obtained for briquettes made of sawdust, crushed plants or crushed cones. However, other authors have not studied a briquette made of this type of material. For example, Gendek et al. [10] obtained a durability factor of $87-97 \%$ for briquettes made of shredded pine, spruce and larch cones, Temmerman et al. [11] $>90 \%$ for sawdust briquettes of various types of wood, 
Ivanova et al. [12] 84-97\% and Lisowski and Świętochowski [5] 80-94\% for briquettes made of miscanthus and its mixtures. The obtained results of the briquette's mechanical durability confirm also the statements of Tumuluru et al. [13] and Križan [14] that, in general, the durability of the briquette is inversely proportional to the particle size, because smaller particles have a larger surface, which results in better bonding In the discussed studies, the highest value of the durability coefficient was obtained for the mixture of $50 \%$ of the fraction $0-1 \mathrm{~mm}, 25 \%$ of the fraction $1-4 \mathrm{~mm}, 25 \%$ of the fraction $4-8 \mathrm{~mm}$, compacted at the temperature of $103{ }^{\circ} \mathrm{C}$.

Table 3. Durability coefficient for varied fractional composition of biomass compacted in two temperatures 73 and $103{ }^{\circ} \mathrm{C}\left(F_{(2,24)}=7.34 ; p=0.0033, \mathrm{SE}=0.01\right)$.

\begin{tabular}{|c|c|c|c|c|c|}
\hline \multicolumn{4}{|c|}{ Share of Fraction, \% } & \multirow{2}{*}{ Temp., ${ }^{\circ} \mathrm{C}$} & \multirow{2}{*}{ Durability Coefficient $( \pm$ SD) } \\
\hline $0-1 \mathrm{~mm}$ & $1-4 \mathrm{~mm}$ & $4-8 \mathrm{~mm}$ & 8-16 mm & & \\
\hline \multirow[t]{2}{*}{50} & 25 & 25 & 0 & 73 & $68.1( \pm 6.2)$ \\
\hline & & & & 103 & $72.5( \pm 3.0)$ \\
\hline \multirow[t]{2}{*}{75} & 0 & 0 & 25 & 73 & $42.0( \pm 2.9)$ \\
\hline & & & & 103 & $67.4( \pm 5.2)$ \\
\hline \multirow[t]{2}{*}{75} & 0 & 25 & 0 & 73 & $64.2( \pm 5.9)$ \\
\hline & & & & 103 & $50.9( \pm 5.3)$ \\
\hline \multirow[t]{2}{*}{75} & 25 & 0 & 0 & 73 & $51.1( \pm 1.04)$ \\
\hline & & & & 103 & $66.1( \pm 2.7)$ \\
\hline
\end{tabular}

The above statement confirms the literature information, which shows that briquettes obtained from fine fractions have a greater durability. This is due to the greater possibility of fitting the particles and the formation of bonds between them. Similarly, increased temperature (up to $103^{\circ} \mathrm{C}$ ) has a positive effect on the durability of the briquettes. It causes the plasticization of substances contained in the biomass, the release of resins and, as a result, better binding of the compacted material.

The conducted research proves the suitability of the shredded logging residues for the production of solid fuels in the form of briquettes. It would be important to continue research, in particular, on the construction of the compacting device (including determination of die height and compaction pressure).

\section{Conclusions}

On the basis of the conducted research, it was found that the elemental composition of the tested biomass differs from the composition of other compared raw materials. However, it is advantageous for a raw material for the production of solid fuels.

The most favorable, though unsatisfactory, value of the durability coefficient was obtained for the compaction of wood chips with a moisture content of $10 \%$ and a temperature of $103^{\circ} \mathrm{C}$.

The fractional composition of the compacted biomass affects the value of the durability coefficient. The most favorable results among the tested mixtures were obtained for the composition $50 \%$ of the $0-1 \mathrm{~mm}$ fraction, $25 \%$ of the $1-4 \mathrm{~mm}$ fraction, $25 \%$ of the $4-8$ mm fraction.

Author Contributions: Conceived and designed the experiments T.N. and A.G.; performed the experiments T.N. and A.G.; analyzed the data T.N., A.G. and M.D.; writing-original draft preparation, review and editing T.N.; A.G. and M.D.; supervision T.N. All authors have read and agreed to the published version of the manuscript.

Funding: This research was partially funded by WFS fund of Warsaw University of Life SciencesSGGW.

Conflicts of Interest: The authors declare no conflict of interest. 


\section{References}

1. Reva, V.; Fonseca, L.; Lousada, J.L.; Abrantes, I.; Viegas, D.X. Impact of the pinewood nematode, Bursaphelenchus xylophilus, on gross calorific value and chemical composition of Pinus pinaster woody biomass. Eur. J. For. Res. 2012, 131, 1025-1033, doi:10.1007/s10342-011-0574-5.

2. Wielgosiński, G.; Łechtańska, P.; Namiecińska, O. Emission of some pollutants from biomass combustion in comparison to hard coal combustion. J. Energy Inst. 2017, 90, 787-796, doi:10.1016/j.joei.2016.06.005.

3. Sulaiman, S.A.; Roslan, R.; Inayat, M.; Yasin Naz, M. Effect of blending ratio and catalyst loading on co-gasification of wood chips and coconut waste. J. Energy Inst. 2017, doi:10.1016/j.joei.2017.05.003.

4. Aniszewska, M.; Gendek, A.; Drożdżek, M.; Bożym, M.; Wojdalski, J. Physicochemical properties of seed extraction residues and their potential uses in energy production. Rocz. Ochr. Śr. 2017, 19, 302-334.

5. Lisowski, A.; Świętochowski, A. Mechanical durability of pellets and briquettes made from a miscanthus mixture without and with the separation of long particles. Pol. Soc. Agric. Eng. 2014, 1, 93-100.

6. Nurek, T.; Gendek, A.; Roman, K. Forest Residues as a Renewable Source of Energy: Elemental Composition and Physical Properties. BioResources 2019, 14, 6-20, doi:10.15376/biores.14.1.6-20.

7. Nurek, T.; Gendek, A.; Roman, K.; Dąbrowska, M. The effect of temperature and moisture on the chosen parameters of briquettes made of shredded logging residues. Biomass Bioenergy 2019, 130, 105368, doi:10.1016/j.biombioe.2019.105368.

8. Nurek, T.; Gendek, A.; Roman, K.; Dąbrowska, M. The Impact of Fractional Composition on the Mechanical Properties of Agglomerated Logging Residues. Sustainability 2020, 12, 6120, doi:10.3390/su12156120.

9. Sadhukhan, A.K.; Gupta, P.; Saha, R.K. Modelling of pyrolysis of large wood particles. Bioresour. Technol. 2009, 100, 3134-3139, doi:10.1016/j.biortech.2009.01.007.

10. Gendek, A.; Aniszewska, M.; Malaták, J.; Velebil, J. Evaluation of selected physical and mechanical properties of briquettes produced from cones of three coniferous tree species. Biomass Bioenergy 2018, 117, 173-179, doi:10.1016/j.biombioe.2018.07.025.

11. Temmerman, M.; Rabier, F.; Daugbjerg Jensen, P.; Hartmann, H.; Böhm, T. Comparative study of durability test methods for pellets and briquettes. Biomass Bioenergy 2006, 30, 964-972, doi:10.1016/j.biombioe.2006.06.008.

12. Ivanova, T.; Kolarikova, M.; Havrland, B.; Passian, L. Mechanical durability of briquettes made of energy crops and wood residues. In Proceedings of the Engineering for Rural Development, Jelgava, Latvia, 29-30 May 2014; Latvia University of Life Sciences and Technologies: Jelgava, Latvia, 2014; Volume 13, pp. 131-136.

13. Tumuluru, J.S.; Wright, C.T.; Kenny, K.L.; Hess, J.R. A Review on Biomass Densification Technologies for Energy Application; INL/EXT-10-18420, 1016196; Idaho National Laboratory: Idaho Falls, ID, USA, 2010; p. 85.

14. Križan, P. Research of factors influencing the quality of wood briquets. Acta Montan. Slovaca 2007, 12, 223-230. 